\title{
Judging the soaps
}

\author{
Susan Quilliam
}

\section{Background}

Go on, admit it. However much you may dismiss soap operas, at some point in your life you've been fascinated by them. Maybe as a teenager coming home early from school, as a medical student taking a break from exams, or as a young parent at home with the children, you too have been drawn into the world of 'The Street' or 'The Square' - or even 'The Police Station'. You too have been hooked by a serial drama on radio or television - fast-paced, plotdriven, character-heavy and significance-light, with several cliff-hanger story lines to draw addicts on from one episode to the next.

$$
\begin{gathered}
\text { Soaps are today's town criers, } \\
\text { reflecting and defining the modern } \\
\text { way of life. }
\end{gathered}
$$

Soaps began in the 1930s on American radio and are now a worldwide phenomenon: Wikipedia lists 244 past and present in 19 countries including Japan, Argentina and Poland. Soaps are today's town criers, reflecting and defining the modern way of life. Yes, they are exaggerated and impossibly crisis-laden - but all over the globe, millions follow them avidly.

\section{Soaps as sex education?}

So here's a thought. Could soaps be used for worthwhile purposes as well as for entertainment? We know that young people in particular get a large proportion of their information about sex and sexual health from the media and that media coverage of medical issues often encourages patients of all ages to think through those issues. Surely the soaps' wide reach could be used to spread the word about the issues we Journal readers know are important? What a wonderful medium they could be for health education - if we could regularly slide in those messages that we long to get across to the public about condoms, STIs or smear tests.

\section{One decent soap episode is worth a thousand leaflets in schools.}

It's a good thought - but of course it's not new. The British radio soap, The Archers, was launched in 1951 as a post-war information service to farmers, while Emergency Ward 10 was originally conceived as propaganda for the NHS. And today, health organisations positively queue up to try to persuade the soaps to cover 'their issue'. Lisa Power of the Terrence Higgins Trust, quoted on the BBC website (www.bbc.co.uk), commented that "one decent soap episode is worth a thousand leaflets in schools", while Ian Banks of the Men's Health Forum, also quoted on the $\mathrm{BBC}$ website, suggested that "soap storylines could

J Fam Plann Reprod Health Care 2006; 32(3): 197-198

\section{Cambridge, UK}

Susan Quilliam, BA, Cert Ed, MNLP, Freelance Writer, Broadcaster and Agony Aunt

Correspondence to: Ms Susan Quilliam.

E-mail: susan@susanquilliam.com improve public awareness of health issues far better than government health agencies".

And 'better' is often beyond our wildest dreams. When Coronation Street character, Alma Sedgewick, died of cervical cancer in 2002, the take-up of smear tests in Manchester increased by $21 \% .1$ When British soap EastEnders included their first HIV-positive character, Mark Fowler, the coverage both demystified and undemonised the disease. South Africa's most popular soap opera, Soul City, has an overtly AIDS-fighting message, and the US Agency for International Development has so far invested over US\$127 million in AIDS education through entertainment.

\section{Getting it wrong}

Our first reaction may be: "What a result!". But our second reaction could well be: "What a crime that they aren't doing it better". Because surely the soaps could cover more issues, more frequently, and in more depth. From the professionals' point of view it can feel a criminal waste of opportunity that this highly influential medium isn't doing more for the public good.

And it can feel a criminal waste of energy that when it does do more, it often does it inaccurately. For example, in the interests of drama, soap producers often skew the storylines in favour of 'dramatic' plotlines, namely those involving pain and suffering. So Alma Sedgewick's previously mentioned cervical cancer occurred without symptoms and after one missed smear test - a subsequent study criticised the story line for unduly worrying audiences. ${ }^{2}$ While Mark Fowler's eventual death from AIDS - at a time when new advances in treatment were helping sufferers live much longer - was also criticised, by the Terence Higgins Trust.

\section{As soap characters move into a clinch, we never see them discussing the 'pros and cons' of having sex.}

On the other hand, due to the pace at which events happen in soap episodes, they can present an overoptimistic view of medical matters. In EastEnders, Peggy Mitchell's breast cancer storyline had her tested and diagnosed within days - presumably leaving patients all round Britain fretting when they didn't receive the same speed of health care. Plus, characters can respond to their medical condition in a way that is overoptimistic. A soap character's too quick recovery from a particular condition may not only be inaccurate, but also have a negative impact on viewers who have struggled with the same condition for years.

\section{Avoiding the responsibility}

It's not just a question of why soaps don't cover more sexual health issues, more often and more accurately. We should also call to account why they don't tackle the issues more responsibly. As soap characters move into a clinch, we never see them discussing the 'pros and cons' of having sex. As they move towards the bedroom, we never see a shot of condoms on the bedside table. Pregnancy is often portrayed not as a thought-through choice but as a way to get attention in one's peer group or a way to hold on to a man who threatens to stray. 
One of the problems here is that soaps are so rarely driven by a commitment to the issue. If a producer does choose a reproductive health theme, the first motivation is typically ratings - and all too often that means the plot must move at double-speed with no time for a realistic conclusion, while characters need to display exaggerated emotions with no room for careful decision-making.

Plus, any sense of moral message can get turned on its head as the innocent suffer - or worse still, get written out of the soap - while the villains survive because they grab more ratings. In the soaps, bad sexual behaviour often has few negative consequences, while irresponsible characters get 'caught' rather than 'taught'.

\section{More not better?}

So, soaps should tackle sexual health issues more, more often, and more responsibility - and they should start doing it now. Actually, no. If we argue things a slightly different way, there's actually much to be said in direct opposition to the points I've just been making.

To begin with, the 'why don't they cover more' accusation. The main counter argument here is that it probably wouldn't work. Soaps are designed to appeal to an audience that likes its information presented in short, sharp bites. And that's the reason why there are always several storylines in any one episode, each covered in several segments of a few minutes each and with a huge variation over time in topic and subject matter. Like it or not, more or more in-depth coverage of sexual health themes would bore the audience - hence they would miss the very messages we want them to hear because they would turn off in droves. Alternatively, they would overrespond in droves. The Alma Sedgewick storyline is estimated to have cost the NHS $£ 500,000$ in increased smear tests, many of them for women who had been tested only a short time before.

Finally, while it's persuasive to argue for increased coverage of issues, realistically less may be more. Research seems to hint that the more a soap covers any one message, the more quickly the message fades for the public. The soaps' high-intensity scheduling may simply not be the correct format to effectively convey a sexual health agenda.

\section{Accuracy impossible, responsibility counterproductive?}

But even if the soaps are wise to not overexpose the health message, surely when they do they could be more accurate and realistic? Not necessarily. The whole point of drama is that it may reflect, but never simply copy, real life. It may engage its audience, but typically doesn't - and arguably shouldn't - distract that audience from its emotional involvement by conveying too much hard information. Soaps would probably sign their own death warrant if they went for too much factual reality.

\section{Soaps would probably sign their own death warrant if they went for too much factual reality.}

In any case, to be philosophical for a moment, what is 'reality'? Whether we like it or not, the reality of the situation is that people often do behave like soap characters. They do have unprotected sex with inappropriate partners. They do forget to go for smear tests. And they do get overcome by passion and forget any sense of responsibility. We may not like it, but sexual health professionals' view of the way the world should work can just as unrealistic as soaps' view of the way the world does work.

Which leads us neatly on to the third accusation, namely that soaps should be more responsible. Once again, such an approach may simply be ineffective. Include too many obviously moral messages, and the public - who are bright enough to recognise a sermon when they see one would turn off both metaphorically and literally. As indeed they did when the Northern-based soap opera, Brookside, became too issue-driven; every episode ended with a phone helpline, and television insiders claim that the series' demise in 2003 was precisely because of that fact.

\section{Any solution?}

So is there a way round all this? Can we use the soaps to put across a sexual health education message in a way that has any effect at all?

Well yes, there may be. Earlier this year I attended a Medical Journalists' Association forum on TV coverage of medical issues. Representatives from the soaps claimed that when it came to transmitting a health agenda, they were doing the job. They argued that to put across a sexual health message effectively one needed to do it not regularly, not accurately, not necessarily morally - but dramatically.

$$
\begin{aligned}
& \text { To put across a sexual health message } \\
& \text { effectively one needs to do it not } \\
& \text { regularly, not accurately, not necessarily } \\
& \text { morally - but dramatically. }
\end{aligned}
$$

They claimed that the best way forward is to take an issue, to include it in the soap with some facts though not too many, then within the structure of the drama to expose it to debate. To have characters challenge the issue, struggle with it, fight over it and, through that, provoke the audience into thinking about it. To set up a conflict, and in the heat of that conflict present the message. Then the audience would really pay attention and think through the issues for themselves.

\section{Summing up}

So what's the verdict? Are the soap advocates right to claim that, actually, these programmes are doing as good as job as they can, albeit not in the way we might want them to? Regular readers of this column will know that I usually have a strong opinion on everything. But here I don't feel there is an obvious right call.

Yes, I desperately want to see sexual health issues covered more widely, more fully, more responsibility and ethically. And I want to use any avenue and any medium I can to promote that cause. But I do also appreciate the soap viewpoint: that drama works in a subtly different way from information giving. I'm not claiming that all soaps achieve the ideal of shifting audience attitude through the dramatic process. But I do take the point that when such programmes succeed in encouraging viewers to actively engage with issues - not just passively receiving information but feeling strongly, talking loudly, debating passionately - then the message will truly get across. And because of that, I have to say that when it comes to judging the soaps, for me the jury is still out.

References
1 Howe A, Owen-Smith V, Richardson J. The impact of a television soap opera on the NHS cervical screening programme in the north west of England. J Public Health Med 2002; 24: 299-304.

2 Richardson J, Owen-Smith V, Howe A. The effect of "Alma's" death on women attending for a cervical smear: a questionnaire survey. J Public Health Med 2002; 24: 305-306. 